\title{
Traumatic spinal cord injuries in Turkey
}

F Dincer MD ${ }^{1}$ A Oflazer MD,${ }^{2} \mathrm{M}$ Beyazova MD ${ }^{3} \mathrm{R}$ Çeliker MD,${ }^{1} \mathrm{O}$ Basgöze MD,${ }^{1}$ $\mathrm{K}$ Altioklar $\mathrm{MD}^{2}$

${ }^{1}$ Department of Physical Medicine and Rehabilitation, Hacettepe University School of Medicine, Department of Physical Medicine and Rehabilitation, Ankara; ${ }^{2}$ The Rehabilitation Centre of Ankara; ${ }^{3}$ Department of Physical Medicine and Rehabilitation, Gazi University School of Medicine, Ankara, Turkey.

Spinal cord lesions have various aetiologies, and trauma is one of the leading causes. Patients with spinal cord injuries (SCI) often have motor, sensory and autonomic dysfunctions and require a multidisciplinary rehabilitation programme. In this study 1694 SCI patients were investigated, including the frequency, and the distribution by age, sex, profession, aetiology, clinical status and year of occurrence. Traumatic SCI is more frequent among males than females and among those between the ages of 15 and 39 years. Regarding the aetiology, traffic accident comprised $35.41 \%$ of the total cases, the second most common cause was falls with $29.51 \%$, and the third was high velocity bullet wounds: $21.95 \%$.

Key words: traumatic spinal cord injury; epidemiology; rehabilitation; Turkey.

\section{Introduction}

Trauma has become one of the most dangerous causes threatening human health. Traffic accidents are one of the leading causes and, in Turkey and throughout the world, traffic accidents and high velocity bullet wounds are still the commonest causes of trauma. Other causes are knife wounds, falls from heights, and landslide accidents. ${ }^{1-9}$ Most of the patients referred to the largest rehabilitation centre of our country have a serious traumatic spinal cord injury and are of great importance. For these reasons, patients from this group admitted to our hospital between 1974-1.985 have been surveyed.

\section{Material and methods}

In this study patients referred to our department between 1974-1985 were investigated. A total of 7474 patients were admitted as inpatients to the rehabilitation programme at the Ankara Rehabilitation Centre during this period, and 1694 of them had had a

Correspondence: Adakale sok. No: 21/15. KizilayAnkara, Turkey. traumatic spinal cord lesion. We evaluated these patients in a retrospective study. Of the 1694 patients, $1282(75.68 \%)$ were male and $412(24.32 \%)$ were female. The distribution of traumatic spinal cord injuries according to age, cause, profession, clinical status and year of occurrence are recorded.

\section{Results}

The distribution of traumatic spinal cord lesions according to age is shown in Figure 1. The youngest patient was one year old and the eldest 70 years old, with a mean age of 26.8 years. The high percentage in the 15-39 years age group is striking. One thousand two hundred and twenty four $(72.23 \%)$ of the cases are included in this group. The 15-19 age group with 316 $(18.65 \%)$ patients is the highest risk group. The distribution of patients according to profession is shown in Figure 2. The main group were housewives 338 (19.95\%); next came agricultural workers with 336 $(19.83 \%)$, and then third private industry workers consisting of $330(19.48 \%)$ patients. Most of the housewives were from agricultural regions, being unpaid but contributing to the work force on the farm. This group 


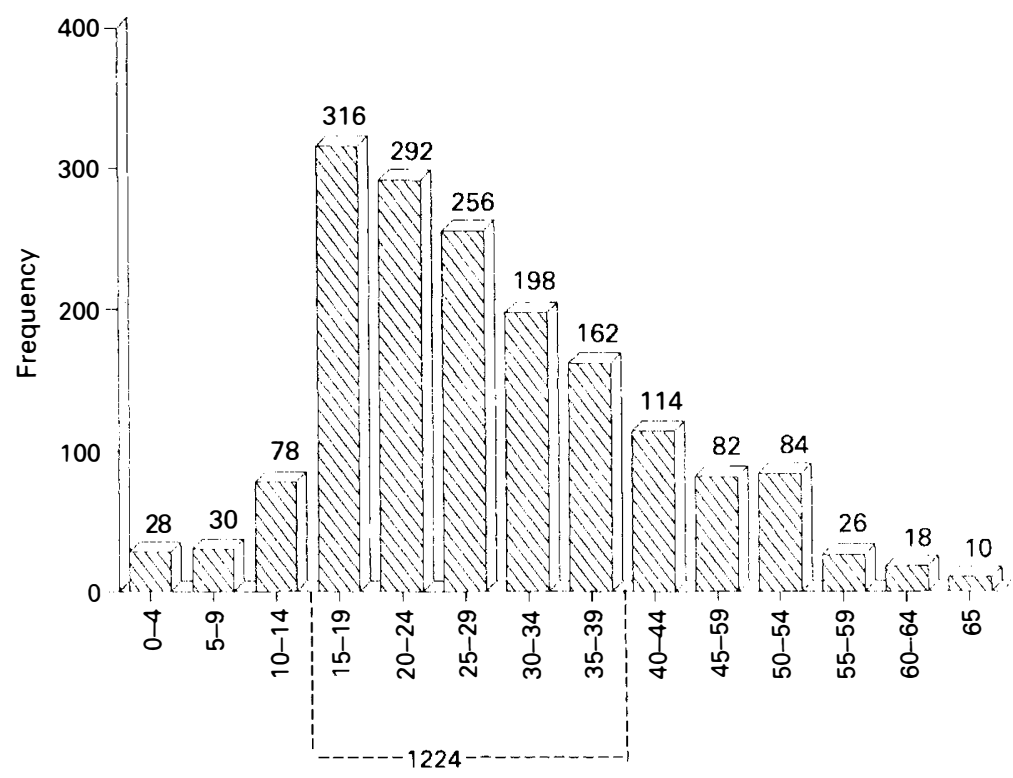

$\% 72.23$

Figure 1 Distribution according to age.
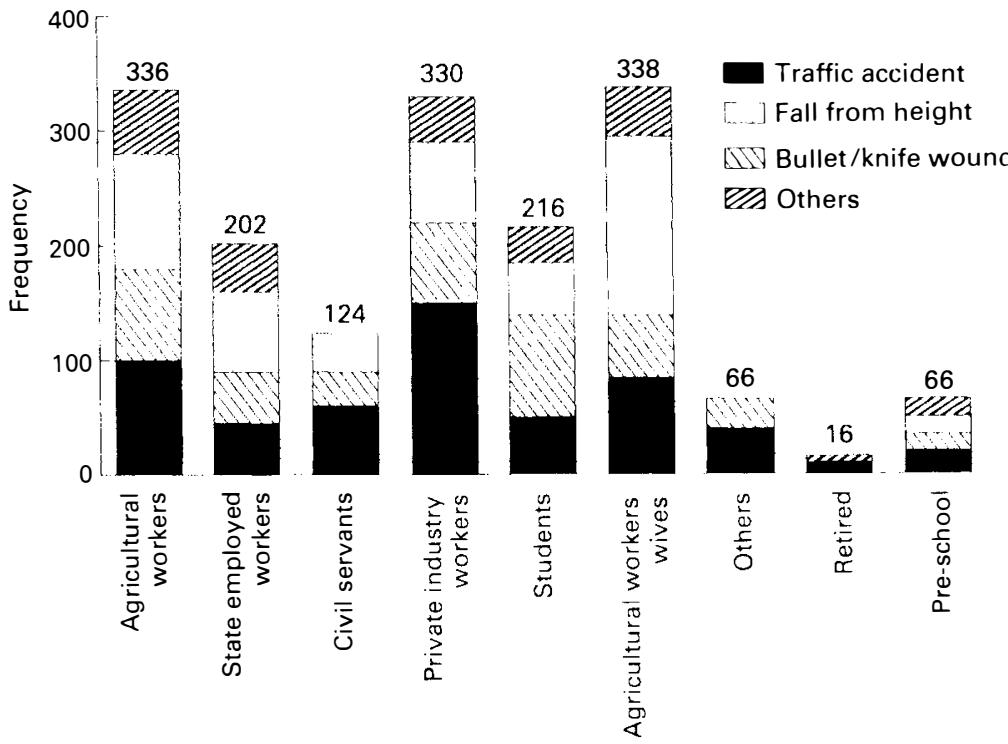

Figure 2 Distribution according to occupation.

together with agricultural and private industry workers are clearly the groups most exposed to spinal cord injury. As is shown in Figure 2, private industry workers have the highest frequency of traffic accidents; the student groups of bullet or knife wounds, and housewives of falls from a height. In our study the distribution of aetiology of trauma in males is: $37.3 \%$ for traffic accidents, $26.4 \%$ for falls, and $24.2 \%$ for gunshot 
injuries. In the female population these ratios are $44.7 \%$ for falls, $29.6 \%$ for traffic accidents and $15.0 \%$ for gunshot injuries.

Distribution analysis of traumatic spinal cord injuries according to the clinical status shows that $1442(85.12 \%)$ cases have complete paraplegia, $116(6.85 \%)$ have incomplete paraplegia, $82(4.84 \%)$ have complete quadriplegia and $54(3.19 \%)$ have incomplete quadriplegia. The distribution of patients according to cause is shown in Figure 3. The type of trauma can be divided into 5 groups: traffic accidents, bullet wounds, knife wounds, falls from a height, and others. Falls from trees constitute most of the falls group. In the 'others' group, causes such as landslide accidents, crushing, compression and lifting heavy loads are included. Traffic accidents are the chief cause with $600(35.41 \%)$ patients, followed by falls from heights $500(29.51 \%)$ cases, and high velocity bullet wounds $372(21.95 \%)$ cases. The distribution of patients according to the year of occurrence is shown in Figure 4. The $1978-79$ period is first with a $23.96 \%$ frequency, second is the 1976-77 period with $23.84 \%$ and third the $1980-81$ period with $21.01 \%$. In the $1980-81$ period SCI

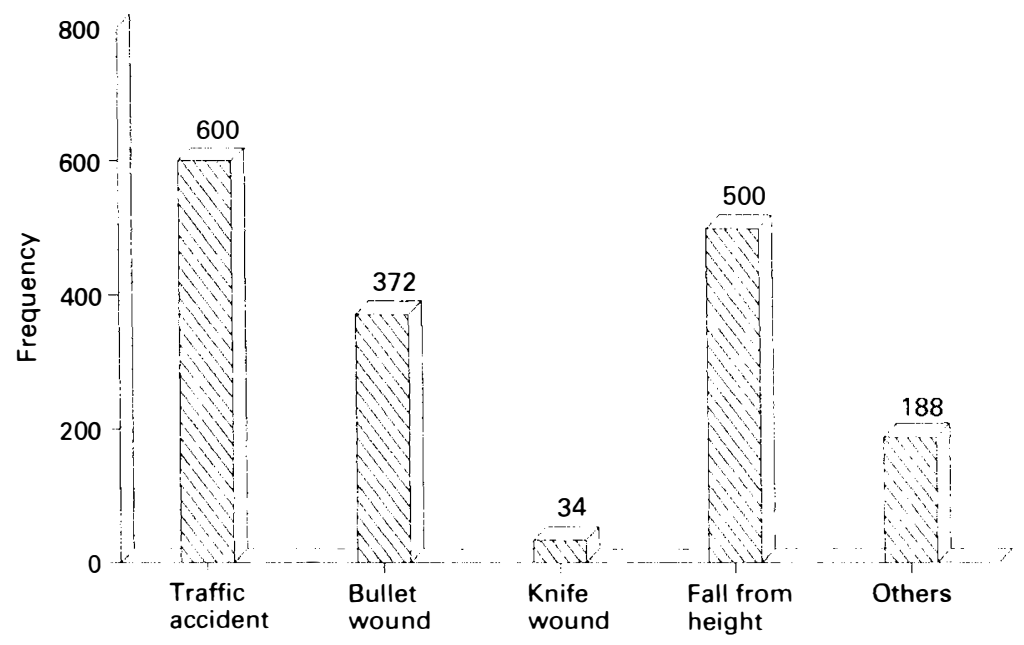

Figure 3 Distribution according to aetiology.

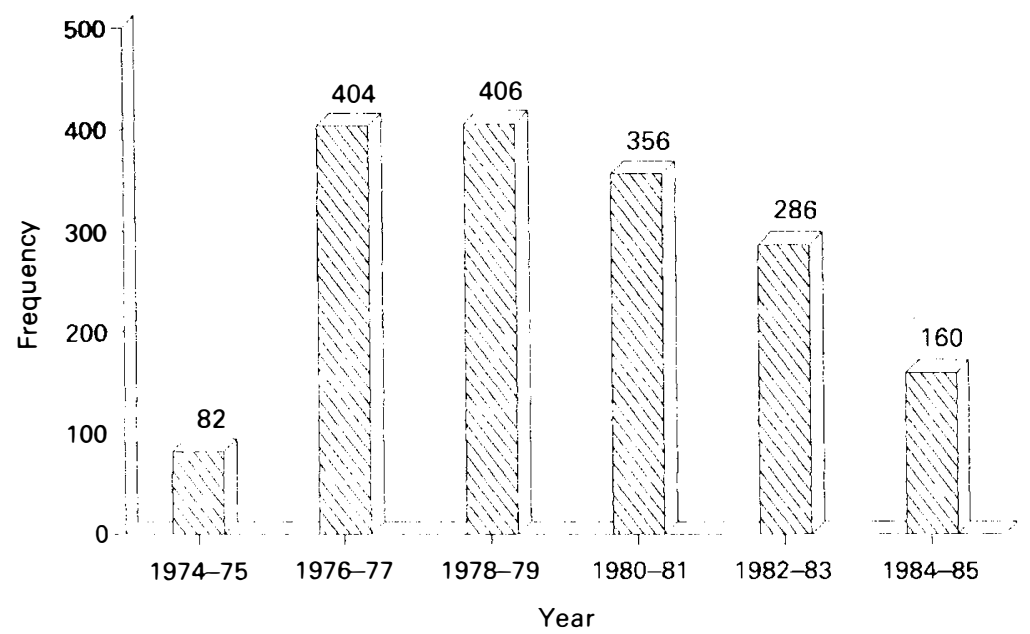

Figure 4 Distribution according to year of occurrence. 
shows a fall in frequency to $16.88 \%$. The types of trauma for each year are given in Figure 5.

\section{Discussion}

In our study we found that men were far more exposed to spinal cord injuries than women, with a ratio of $3: 11$, and reports in the literature support this finding. The male/female ratio was 7.0 in Nigeria, ${ }^{10} 4.8$ in Norway, ${ }^{11} 3.68$ in France ${ }^{12,13}$ and 3 in Spain. ${ }^{14}$ In our series the mean age was 26.8 years, and the 15-39 year age group was noted to be a high risk group with a $72.73 \%$ frequency. The high risk group for traffic accidents is the 15-34 age group, for falls the 15-40 age group and for bullet wounds the 15-30 age group. In 1983, Iwegbu ${ }^{10}$ carried out a survey in Nigeria in which the mean age was 24 years (15-60 years) and the 20-35 age group made up the highest risk group with a $83.3 \%$ frequency. In the 1983 survey carried out by Minaire et al ${ }^{13}$ in France, the mean age was 32.5 years (6-91 years) and the 15-55 age group was the highest risk group with a $80 \%$ frequency. In another study from France covering the 1970-75 period, the mean age was 29.3 years and the 15-60 age group was the highest risk group with a $79 \%$ frequency. ${ }^{12}$ In a study from Norway, the authors reported that the mean age was 37 , and the 15-40 age group was the highest risk group with a $52 \%$ frequency. ${ }^{11}$ In Spain, in the

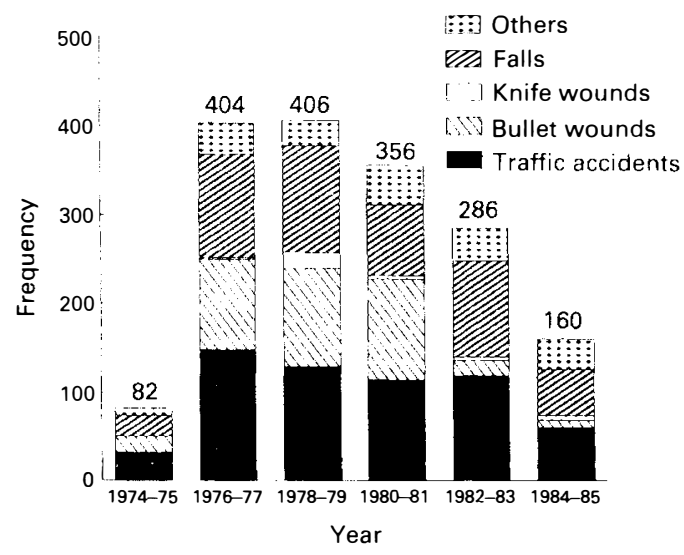

Figure 5 Type of trauma each year. report of Garcia-Reneses et $a^{14}$ the average age was 41.8 and a high incidence was found between 20-30 years of age. Comparing our findings with those in the literature, we found that there was a younger age group constituting the highest risk group for SCI (15-18).

In the distribution of frequency according to profession in our patients the highest was in housewives, followed by agricultural workers and private industry workers. The agricultural workers' wives group stands out among the different groups as the one where people are most exposed to the possibility of a spinal cord injury. Minaire et al ${ }^{12}$ reported that the commonest group was farmers with a $30.5 \%$ incidence, the private sector being second with $27.7 \%$. Similar surveys carried out in France, Burma and our country draws attention to the fact that agricultural workers and private industry workers are the groups most exposed to spinal cord injuries.

The frequency distribution of spinal cord injuries according to year in our survey shows that the 1978-79, 1976-77 and 1980-81 periods were the top 3. Although no characteristic feature is seen in the distribution of other trauma types according to year, the frequency of high velocity bullet wounds between 1976-81 was greatly decreased in 1980 and 1981 . This was due to the military curfew and security measures taken during these years. Only traffic accidents and falls show a difference according to months; July, June and August take the first 3 places, then May and September. Increase in tourism during these months can be regarded as the reason for these differences. Falls from trees, which make up the majority of falls for heights, are most common during July, August and September, the reason being the increase in agricultural work during this period.

In our survey of 1694 patients, the leading cause of trauma was traffic accidents with a $35.41 \%$ frequency, being followed by falls from heights with $29.51 \%$ and bullet wounds with $21.95 \%$. The most frequent causes of trauma were falls and traffic accidents for agricultural workers; falls and traffic accidents for state employed workers; traffic accidents and gunshot injuries for civil servants; traffic accidents and falls for 
private industry workers; gunshot injuries and traffic accidents for students; and falls and traffic accidents for housewives. In the study from Nigeria traffic accidents were the leading cause with a $75 \%$ frequency, followed by falls from heights with $23 \% .{ }^{10}$ In Spain traffic accidents are the commonest cause of trauma, falls being next in frequency. ${ }^{14}$ In France, traffic accidents are also the leading cause $(50.7 \%)$, followed by falls from a height $(31.5 \%)$ and bullet wounds $(2.0 \%) .{ }^{13}$ These ratios are $48.7 \%$ for traffic accidents, $26.6 \%$ for falls, $5.8 \%$ for gunshot injuries in Australia; ${ }^{12} 46.8 \%$ for traffic accidents, $25.7 \%$ for falls, $0 \%$ for gunshot injuries in England; and $42.8 \%$, $19.2 \%$ for falls and $12.3 \%$ for gunshot injuries in America. ${ }^{7.12 .15 .16 .17}$ According to the study from Burma, falls take priority with a $70 \%$ frequency, the second is traffic accidents with $14 \%$ and $3 \%$ for gunshot injuries. ${ }^{18}$ Traffic accidents and falls are the commonest cause of spinal cord trauma in the literature and in our patients. However, the ratio of gunshot injuries is higher than in other countries. This is the result of anarchy and terrorism in our country pre 1980, and is evident in the trauma aetiology according to the year of occurrence.

The distribution of our patients with a SCI according to the clinical presentation are $8.1 \%$ complete and incomplete quadriplegia, and $91.9 \%$ complete and incomplete paraplegia. According to the studies of Minaire et al $^{12.13}$ these ratios are $30.8 \%$ -
$33.2 \%$ for quadriplegia and $69.2 \%-$ $66.8 \%$ for paraplegia. According to the study of Richardson and Meyer ${ }^{8}$ in 1981 in America these ratios were $49.0 \%$ and $51.0 \%$ and according to the studies from Nigeria and South Africa, the ratios given were $11.1 \%-89.9 \%$ and $23.0 \%-77.0 \%$ respectively. ${ }^{10,19}$ It is obvious that spinal cord trauma in the cervical region is seen less frequently. This ratio in our country is lower than is reported in other countries. Among spinal traumatic and non traumatic cord injuries, traumatic aetiology was found to cause the highest death rate during the first weeks, especially among those with high cervical lesions. ${ }^{14}$ Complete lesions $(89.96 \%)$ were more likely than incomplete lesions to have a fatal outcome. Complete/incomplete is $8 / 1$ in Nigeria ${ }^{10}$ and $1 / 1$ in Norway ${ }^{11}$ and America. ${ }^{7}$ In our country and in Nigeria this ratio is high and shows that in developing countries emergency and first aid service and post-traumatic care is not sufficient. In addition delayed arrival at the centre and inadequate primary treatment are important factors in the low incidence of tetraplegics admitted to our centre.

We believe that many types of injuries especially traffic accidents can be prevented. A series of socioeconomic measures, including primarily mass education will have beneficial results. In addition, we consider it necessary to apply more effective preventive measures to reduce the number of traffic and industrial accidents.

\section{References}

1 Walsh JW. Stevens DB, Young AB (1983) Traumatic paraplegia in children without contiguous spinal fracture or dislocation. Neurosurgery 12: 439-445.

2 Cloward RB (1982) Acute cervical spine injuries. Clinical Symposia 32: 1.

3 Gilroy J, Meyer JS (1979) Medical Neurology. 3rd ed. Macmillan Publishing Co. Inc, New York: $513-517$.

4 Guttmann L (1975) Spinal Cord Injuries. Blackwell Scientific Publications. London; 89-121, 159-165, $170-174$.

5 Goodgold J (1988) Rehabilitation Medicine. The C.V. Mosby Company, St Louis: 147-183.

6 Keim HA, Kirkaldy-Willis WH (1980) Low back pain. Clinical Symposia 32: 6.

7 Griffin MR. Opitz JL, Kurland LT, Ebersold MJ. O'Fallon WM (1985) Traumatic spinal cord injury in Minnesota, 1935-1981. Am J Epidemiol 121: 884-895.

8 Richardson RR, Meyer PR (1981) Prevalance and incidence of pressure sores in acute spinal cord injuries. Paraplegia 19: 235-247.

9 Youmans JR (1982) Neurological Surgery. WB Saunders Company, Philadelphia: 1041-1088.

10 Iwegbu CG (1983) Traumatic paraplegia in Zaire. Nigeria: the case for a centre for injuries of the spine. Paraplegia 21: 81-85.

11 Gjone R, Nordlie L (1978) Incidence of traumatic paraplegia and tetraplegia in Norway: a statistical survey of the years 1974 and 1975. Paraplegia 16: 88-93.

12 Minaire P, Castanier M, Girard R, Berard E, Deidier C, Bourret J (1978) Epidemiology of spinal cord 
injury in the Rhone-Alpes Region, France, 1970-1975. Paraplegia 16: 76-78.

13 Minaire P, Demolin P, Bourret J, Girard R, Berard E, Deidier C et al (1983) Life expectancy following spinal cord injury: a ten years survey in the Rhone-Alpes region, France, 1969-1980. Paraplegia 21: 11-15.

14 Garcia-Reneses J, Herruzo-Cabrera R, Martinez-Moreno M (1991) Epidemiological study of spinal cord injury in Spain 1984-1985. Paraplegia 29: 180-190.

15 Tator CN, Edmonds VE (1979) Acute spinal cord injury: analysis of epidemiologic factors. Can J Surg 22: 575-578.

16 Staas WE, Formal CS, Gershkoft AM, Freda M, Hirschwald JF, Miller GT et al (1988) Rehabilitation of the spinal cord-injured patient. In: DeLisa JA. editor. Rehabilitation Medicine. 1st ed. J B Lippincolt, Philadelphia: 635-659.

17 Murray PK, Kusior MF (1984) Epidemiology of nontraumatic and traumatic spinal cord injury. Arch Phys Med Rehabil 65: 634.

18 Toe T (1978) Spinal cord injuries in Rangoon, Burma. Paraplegia 16: 118-129.

19 Shrosbree RD (1978) Spinal cord injuries as a result of motorcycle accidents. Paraplegia 16: 102-112. 